Archives of Agriculture and Environmental Science

\title{
Effectiveness of different plant extracts against Galleria mellonella larvae in laboratory
}

\section{Lalita, Yogesh Kumar and Sunita Yadav}

Department of Entomology, CCS Haryana Agricultural University, Hisar 125004, (Haryana), INDIA

"Corresponding author's E-mail: Ialitapanwar17@gmail.com

\section{ARTICLE HISTORY \\ Received: 26 December 2017 \\ Revised received: 21 February 2018 \\ Accepted: 26 February 2018}

Keywords

Galleria mellonella

Honeybees

Larval mortality

Plant extracts

Wax moth

\begin{abstract}
The present investigation was undertaken to study the effectiveness of different plant extracts against Galleria mellonella larvae in laboratory. Acetone prepared extracts of leaves, stem, seed, root, husk of thirteen medicinal and healthy plants were used to examine their effects on the mortality of the greater wax moth Galleria mellonella larvae in laboratory. Results revealed that only six plant extracts prepared with leaves and stem cause mortality of wax moth. Larval mortality was highest (93.33\%) with husk prepared extract of $P$. psyllium followed by leaf prepared extract of H. sativum (80\%), Raphanus sativus (73.33\%), Linum usitatissimum (66.66\%) Cucurbita moschata (46.66\%) and Vicia sativa (46.66\%). The larval mortality with stem/root/seed prepared extract was recorded highest in Hordeum sativum (73.33\%) followed by Raphanus sativus (80\%), Cucurbita moschata (60\%) Linum usitatissimum (53.33\%) and Vicia sativa (40\%) and found significant difference with the control $(0.00 \%)$. There was no mortality of larvae was found in control and other remaining plant extract. Irrespective of the different plants, highest per cent mortality $(52.22 \%)$ of wax moth larvae by stem/seed/ root prepared extract followed by leaf extract (48.66). Therefore, the plant extract of different plants were found effective against Galleria mellonella larvae.
\end{abstract}

(C)2018 Agriculture and Environmental Science Academy

Citation of this article: Lalita, Kumar, Y. and Yadav, S. (2018). Effectiveness of different plant extracts against Galleria mellonella larvae in laboratory. Archives of Agriculture and Environmental Science, 3(1): 64-67 DOI: 10.26832/24566632.2018.030109

\section{INTRODUCTION}

Presently beekeeping industries are facing many challenges throughout the world. Among these, a major constraint in beekeeping developmental programme is the damage caused to honey bee colonies by various enemies and diseases. Honeybees are attacked by many diseases and pests which cause weakness of colonies and low honey production. Greater wax moth Galleria mellonella is one of the most devastating and economically important pests of wax in the world (Burges, 1978; Chang and Hsieh, 1992) and finds mention since the period of Aristotle (284 BC) in his writings on agricultural subjects. The caterpillars of wax moth feeds on combs, pollen, larval exuviae and other proteinaceous matter both in storage as well as in live honey bee colonies (Caron, 1999). Its larval stage feeds on wax and pollen stored in combs of active honey bee colonies (Milam, 1970), freshly extracted combs, impure wax, slum gum, wax capping and queen rearing materials containing wax in the storage (Williams, 1978). The larvae bore in to the combs and make silken tunnels in the middle of the comb and feeding on honey, pollen, wax and brood of honey bees. The entire comb is covered with a mass of webbing and fecal matter of the larvae; a condition described as "Galleriasis".

To the beekeeper, wax moth is one of the serious pests of the honey bee colonies which feeds on comb wax and causes economic loss to the beekeeping industry. Physical methods of cooling and heating colonies were used in controlling $G$. mellonella in the absence of honeybees. Cooling was more effective and more practical since excessive heat damaged combs and spoiled honey (Burges, 1978) and they also reported that the most rapid control of wax month larvae was obtained by deep freezing at $-17^{\circ} \mathrm{C}$, but temperature just above or just below freezing (such as are found in domestic refrigerators) are also effective with an exposure period of 10 to 21 days. Many synthetic chemicals were attempted to control this worm in both hives and storage, but these chemicals are not without drawbacks. These synthetic insecticides cause tainting of honey and other hive products, in addition to their side-effect on bees. Use of chemical insecticides such as sulphur, para dichloro benzene and calcium cyanide is harmful to bee population 
(Whitecomb, 1967). Since the main target in beekeeping operation is the high quality low residue product, it is worthwhile to try such environment safe substances against the wax moth.

In this context, use of plant products as insecticides is emerging as a major thrust area in controlling Greater wax moth. Natural plant products possess insecticidal activity. The plants based insecticides being the natural plant products are safer and hence their use against pests has gained importance all over the world (Alkofahi et al., 1989; Hiremath, 1994). Although plant extracts were examined against many Lepidopterous insects, no studies were conducted to find plant extracts which may cause the mortality of wax moth larvae in laboratory. Identifying a natural compound with high insecticidal activity against the wax moth and with low toxic effects to honeybees is essential. This will enable their use in integrated pest management programs to control wax moth in honeybee colonies as well as in storage areas without contaminating honey bee products with pesticide residues. Therefore, the objective of this study was to investigate the effect of thirteen different extracts of medical and healthy plants grown in the Hisar region on the mortality of wax moth (Galleria mellonellal) larvae. Such methods with non-harmful products could contribute considerably to control this pest and reduce the risks of beehive product contamination and may give a possible solution for this apicultural problem. Keeping in view, the present study was undertaken to study the effectiveness of different plant extracts against Galleria mellonella larvae in laboratory.

\section{MATERIALS AND METHODS}

Experiment was carried out at Apiculture Laboratory of the Department of Entomology, Chaudhary Charan Singh Haryana Agricultural University, Hisar (Haryana), India during year 2015depending upon the availability of the plants in the field.

\section{Culturing of greater wax moth}

Naturally infested honey bee combs with wax moth were obtained from apiaries and taken in the laboratory of the Department of Entomology. To ascertain pure culture, emerged both male and female adult and new generation $5^{\text {th }}$ instar larvae were used for experiments. To rear wax moth larvae, newly emerged wax moth females and males were collected in glass jar $(15 \times 15 \times$ $20 \mathrm{~cm}$ ) and provided sugar syrup for feeding. For feeding, cotton swab was dip in the sugar syrup and hanged inside the glass jar by the muslin cloth. After mating, females were left to deposit eggs in glass jar with partially full of Apis dorsata combs for feeding for emerged larvae which was covered with muslin cloth of $20 \times 20 \mathrm{~cm}$. a piece of hard paper was also put in the glass jar for egg laying. The eggs were incubated in incubator or a warm room at $30^{\circ} \mathrm{C}$, relative humidity of 80 per cent and 24 hours darkness until emergence of adult stages of great wax moth. Directly after emergence 30 adults, 15 male and 15 female of the same age were collected in another glass jar, provided sugar syrup and incubated under the same condition to get the next generation. The larval stages were used as needed with a culture media and experiment purpose.
Preparation of plants extract

Thirteen plants belonging to nine different plant families were used for in this experiment. The tested plants were collected from research farm of the CCS HAU, Hisar. For preparation of plant extracts leaves, stems and seeds of the collected plant materials were dried in shade condition. After drying, each plants material was ground into powdered form by mixture grinder separately. Sample of $20 \mathrm{~g}$ of the ground material was extracted by $85 \%$ acetone.

For testing the effect of plant extracts on the wax moth, the fifth larval instars were choose and collected from the jar to make the investigations. A thin film was made from $45 \mathrm{ml}$ solution of each with acetone prepared plant extracts in three petriplates (15 cm diameter) and left for 15 minute. After drying, 5 larvae with fifth instar were released in each petriplate. Each petriplate will be supplied with 5 pieces of wax $(1 \mathrm{~cm} \times 1 \mathrm{~cm} \times 1 \mathrm{~cm})$ and incubate at $28 \pm 2{ }^{\circ} \mathrm{C}$ temperature and 80 per cent Relative Humidity. A control with no extract was used. Each plant extract was replicated three times in a complete randomized design. Petriplates was daily inspected for dead or unusual sign appeared on the larvae or pupae until the emergence of the adult. The duration of the larval and pupal stages after addition of the plant extract was also recorded.

\section{RESULTS AND DISCUSSION}

Extracts of thirteen different plants belonging to nine plant families were used in this experiment (Table 1) to examine their effects on the larval mortality in laboratory condition. Data presented in Table 2 revealed that only six plant extracts prepared with leaves and stem cause mortality of wax moth (Table 2.) with significant difference $(P \leq 0.05)$ from the untreated control. Larval mortality was highest (93.33\%) with husk prepared extract of $P$. psyllium followed by leaf prepared extract of $H$. sativum (80\%), Raphanus sativus (73.33\%), Linum usitatissimum (66.66\%) Cucurbita moschata (46.66\%) and Vicia sativa (46.66\%). Data in table 2 also indicated the larval mortality with stem/root/seed prepared extract was recorded highest in Hordeum sativum (73.33\%) followed by Raphanus sativus (80\%), Cucurbita moschata (60\%) Linum usitatissimum (53.33\%) and Vicia sativa (40\%) and found significant difference with the control $(0.00 \%)$. Irrespective of the different plants, highest per cent mortality (52.22\%) of wax moth larvae by stem/seed/ root prepared extract followed by leaf extract (48.66). The results are in close proximity with the study of (Zaitoun, 2007) which indicated that feeding the moth larvae on most of the extracts, prolonged the larval stage duration 2-40 days more than the control. Out of 21 plant extracts, four of them showed the highest killing rate. Moth mortality was $100 \%$ with A. precatorius and L. nobilis, 95\% with Petroselinum sativum and P. psyllium, $78.3 \%$ with $H$. sativum and $45 \%$ of the experimental population with N. sativa. Extracts of Abrus precatorius, Laurus nobilis, Petroselinum sativum and Plantago psyllium had insecticidal effect against the moth; they killed 100 or $95 \%$ of the tested wax moths respectively without adverse effects on worker bees except in the case of $A$. precatorius. 
Table 1. List of Scientific name, Family of the plants and plant part used as extract against G. mellonella.

\begin{tabular}{cllll}
\hline S.N. & Common name & Scientific name & Family & Plant part used as extract \\
\hline 1. & Isabgol & Plantago psyllium & Plantaginaceae & Isabgol husk \\
2. & Urad & Vigna mungo & Leguminoceae & Leaves and stem \\
3. & Moong & Vigna radiata & Leguminoceae & Leaves and stem \\
4. & Til & Sesamum indicum & Pedaliaceae & Leaves and stem \\
5. & Alsi & Linum usitatissimum & Linaceae & Leaves and seed \\
6. & Barley & Hordeum sativum & Gramineae & Leaves and stem \\
7. & Pea & Pisum sativum & Fabaceae & Leaves and stem \\
8. & Chickpea & Cicer arietinum & Fabaceae & Leaves and stem \\
9. & Garden vetch & Vicia sativa & Fabaceae & Leaves and seed \\
10. & Pumpkin & Cucurbita moschata & Cucurbitaceae & Leaves and stem \\
11. & Mustard & Brassica juncea & Brassicaceae & Leaves and stem \\
12. & Radish & Raphanus sativus & Brassicaceae & Fabaceae \\
13. & French bean & Phaseolus vulgaris & Where no plant extract was used \\
\hline 14 & Control & & &
\end{tabular}

Table 2. Per cent larval mortality of G. mellonella in different plants extract in laboratory.

\begin{tabular}{llll}
\hline \multirow{2}{*}{ S.N. } & Plants extract & Husk/ Leaf extract & Stem/seed/root extract \\
\hline 1 & Plantago psyllium & $93.33(81.13)$ & - \\
2 & Vigna mungo & $0(0.00)$ & $0(0.00)$ \\
3 & Vigna radiata & $0(0.00)$ & $0(0.00)$ \\
4 & Sesamum indicum & $0(0.00)$ & $0(0.00)$ \\
5 & Linum usitatissimum & $66.66(54.96)$ & $53.33(46.90)$ \\
6 & Hordeum sativum & $80(68.05)$ & $73.33(59.18)$ \\
7 & Pisum sativum & $0(0.00)$ & $0(0.00)$ \\
8 & Cicerarietinum & $0(0.00)$ & $0(0.00)$ \\
9 & Vicia sativa & $46.66(43.06)$ & $40(39.21)$ \\
10 & Cucurbita moschata & $46.66(43.06)$ & $60(51.12)$ \\
11 & Brassica juncea & $0(0.00)$ & $0(0.00)$ \\
12 & Raphanus sativus & $73.33(59.18)$ & $80(68.05)$ \\
13 & Phaseolus vulgaris & $0(0.00)$ & $0(0.00)$ \\
14 & Control & $0(0.00)$ & $0(0.00)$ \\
& Mean & 48.66 & 52.22 \\
& C.D. & 12.96 & 15.48 \\
& SE(m) & 4.45 & 5.31 \\
& SE(d) & 6.29 & 7.52 \\
& C.V. & 30.89 & 37.30 \\
\hline
\end{tabular}

Each value represent mean of three observations; Figures in parentheses are angular root transformed value.

\section{Conclusion}

The present study concluded that only six plant extracts prepared with leaves and stem cause mortality of wax moth with significant difference $(P \leq 0.05)$ from the untreated control. Larval mortality was highest (93.33\%) with husk prepared extract of $P$. psyllium followed by leaf prepared extract of $H$. sativum (80\%), R. sativus (73.33\%), L. usitatissimum (66.66\%) C. moschata (46.66\%) and V.sativa (46.66\%). Data in table 2 also indicated the larval mortality with stem/root/seed prepared extract was recorded highest in $\mathrm{H}$. sativum (73.33\%) followed by R. sativus (80\%), C. moschata (60\%) L. usitatissimum (53.33\%) and V. sativa (40\%) and found significant difference with the control (0.00\%). Irrespective of the different plants, highest per cent mortality (52.22\%) of wax moth larvae by stem/seed/ root prepared extract followed by leaf extract (48.66). Moreover, Extracts of Abrus precatorius, Laurus nobilis, Petroselinum sativum and Plantago psyllium had insecticidal effect against the moth; they killed 100 or $95 \%$ of the tested wax moths respectively without adverse effects on worker bees.
Open Access: This is open access article distributed under the terms of the Creative Commons Attribution License, which permits unrestricted use, distribution, and reproduction in any medium, provided the original author(s) and the source are credited.

\section{REFERENCES}

Alkofahi, A., Rupprecht, J.K., Anderson, J.E., McLaughlin, J.C., Mikolajczak, K.L. and Scott, E.A. (1989). Search for new pesticides from higher plants. In: Insecticides of plant origin, Ed. Amason, J.T. ACS Washington, pp. 25-43.

Aristotle, (284 B.C.). Historia animalium Bk. IX, Ch. 40, Transl. D.W. Thompson, Clerondon press, Oxford, 1910, pp. 633.

Burges, H.D. (1978). Control of wax moth: Physical, Chemical and biological methods. Bee World, 59(4): 129-138.

Caron, D.M. (1992). Wax moth. American Bee Journal. 132(10): 647-649.

Chang, C.P. and Hsieh, F.K. (1992). Morphology and bionomics of Galleria mellonella. Chinian Journal of Entomology, 12 (2): 
121-129.

Hiremath, I.G. (1994). Isolation and identification of pesticides from selected Indian and African plants. Post doctoral research document, Seoul National University, pp. 109.

Milam, V.G. (1970). Moth pests of honeybee combs. Gleanian Bee Culture, 68: 424-428.

Whitecomb, W.J. (1967). Controlling the greater wax moth: A pest of honey comb. Bulletin of the U.S. Department of Agriculture, 217: 12.
Williams, J.L. (1978). Insects: Lepidoptera (Moths). In: Honey bee pests, predators and diseases (ed. Morse, R.A.) Cornell University Press, Ithaca, pp. I05-127.

Zaitoun, S.T. (2007). The effect of different Mediterranean plant extracts on the development of the greater wax moth, Galleria mellonella L. (Lepidoptera: Pyralidae) and their toxicity to worker honeybees Apis mellifera L. (Hymenoptera: Apidae) under laboratory conditions. Journal of Food, Agriculture and Environment, 5(2): 289-294. 